\title{
Correlation among Morphological Awareness, Reading Fluency and Spelling for School-Aged Children with Language-Learning Disabilities in Third to Fourth Grades
}

\author{
Hyo-Jung Han ${ }^{\mathrm{a}}$, Mibae Kim ${ }^{\mathrm{b}}$ \\ a Department of Speech Language Pathology, Graduate School, Catholic University of Pusan, Busan, Korea \\ ${ }^{b}$ Department of Speech Language Pathology, Catholic University of Pusan, Busan, Korea
}

Correspondence: Mibae Kim, PhD

Department of Speech Language Pathology,

Catholic University of Pusan, 57 Oryundae-ro,

Geumjeong-gu, Busan 46252, Korea

Tel: +82-51-510-0845

Fax: +82-51-510-0848

E-mail: mbkim@cup.ac.kr

Received: April 4, 2018

Revised: May 19, 2018

Accepted: May 19, 2018

This work is based on the master's thesis of the first author.

\begin{abstract}
Objectives: There are several linguistic factors affecting reading fluency (RF) and spelling, particularly the factors called metalinguistic abilities such as phonological awareness (PA) and morphological awareness (MA). The 3rd and 4th grades in elementary school are widely known as important periods for developing RF and spelling. Therefore, the study investigated how MA ability affects reading and writing skills of primary students in 3rd and 4th grade. Methods: The research was conducted with students in the 3rd and 4th grade of elementary school. Thirty-two students participated in the research, 16 students with language learning disabilities (LLD) and 16 typically-developing students (TD). The research used RF with accuracy and rate, spelling with phoneme-grapheme correspondent (PGC) writing and phoneme-grapheme non-correspondent writing and MA. MA tasks were divided into compound and derivation. Results: First, the students with LLD showed prominently lower performance in MA tasks than TD students. Second, students with LLD showed slower speed and less accuracy in correspondent and non-correspondent writing tasks than TD students. Third, TD's derivation correlated with RF, reading rate, spelling and PGC scores. In particular, derivative scores were correlated with reading rate. In the LLD group, accuracy was correlated with compound and overall production. Conclusion: TD students use MA to read automatically. This means TD students near the final stages of correspondent writing are influenced by their derivative abilities. Students with LLD also depend on their MA skills to read accurately, and therefore fail to read fluently.
\end{abstract}

Keywords: School-aged children, Language-learning disability, Morphological awareness, Reading fluency, Spelling
읽기의 궁극적인 목적은 읽기이해이며 읽기의 단순 관점(simple view of reading)에서 읽기이해란 해독(decoding)과 언어이해(linguistic comprehension)의 결과물이라고 한다(Hoover \& Gough, 1990). 하지만 최근에는 읽기의 최종 목표인 읽기이해를 해독과 언 어이해로만 설명하는 것은 제한적이라고 하며 해독과 언어이해 능 력 외에 읽기이해에 영향을 주는 요인으로 읽기유창성을 언급한다 (Katzir et al., 2006; Kim, Yoo, Hwang, Kim, \& Koh, 2010; Kim, Wagner, \& Lopez, 2012; Lee \& Kim, 2003; Torgesen \& Hudson, 2006).
읽기유창성이란 글을 노력 없이 빠르게 읽는 능력으로 해독, 이 름대기, 철자인식, 의미, 구문, 형태의 언어적 지식을 통합적으로 보 여주는 능력이다(Katzir et al., 2006). 읽기발달에서 읽기유창성은 해독에서 읽기이해로 넘어가는 시기의 다리 역할을 한다(Bashir \& Hook, 2009). 따라서 읽기유창성은 궁극적인 읽기 목표인 읽기이 해를 성취하기 위하여 숙달되어야 할 중요한 읽기 요소 중 하나이 다. 읽기유창성의 중요성은 Chall (1983)의 읽기 발달 단계에서도 살펴볼 수 있다. 저학년 시기는 읽기를 배우는(learn to read) 단계 
Hyo-Jung Han, et al. • Correlation among Morphological Awareness, Reading Fluency and Spelling

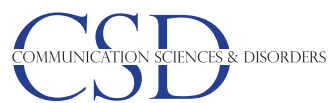

이며 배우기 위한 읽기(read to learn) 단계로 넘어가는 3단계를 기 점으로 해독이 자동화되고 읽기의 속도가 향상되며 복잡한 이해 를 가능하게 하는 단계에 접어든다. Carlisle와 Rice (2002), Wolf (2007)에 의하면 낱말재인(word recognition) 능력의 발달이 늦을 경우 단지 단어를 기억하는 데만 집중을 하게 되어 이해에 방해를 받는다고 한다. 즉 단어 및 단락글을 빠르고 자동적으로 읽게 되는 읽기유창성이 정확한 이해에 요구되는 인지적, 언어적 전략을 통합 하고 계획하는 데 중요한 역할을 한다(Bashir \& Hook, 2009).

Katzir 등(2006)에 의하면 읽기유창성은 이름대기, 철자인식, 해 독뿐만 아니라, 음운론적, 의미론적, 구문론적, 형태론적 과정의 성 공적인 통합의 산물이라고 하였다. 특히 파생, 합성과 같은 분석방 법으로 새로운 단어를 빠르게 읽어낼 수 있는 형태론적 지식은 읽 기의 효율성과 자동성을 증가시킨다. 형태론적 지식은 주어진 단어 의 철자를 시각적으로 보기 쉽게 인식하는 것을 도와주어 더 빨리 읽을 수 있게 해준다. 또한 철자의 빠른 확인을 도와주어 의미적인 이해와 확인 속도를 빠르게 하여 자동적인 읽기와 읽기이해를 돕 는다. 따라서 형태를 파생하고 합성하여 생성을 해내는 형태론적 인식이 이러한 과정의 중심에서 읽기유창성에 중요한 요소로 작용 을 한다. 이 능력은 초등 3-4학년에 해당하는 초등 중학년 시기가 되면 읽기, 쓰기에 활용되는 비중이 커진다고 한다(Apel \& Thomas-Tate, 2009; Berninger, Abbott, Billingsley, \& Nagy, 2001; Wolf \& Katriz-Cohen, 2001).

쓰기는 단순 쓰기 모델(simple view of writing)에 따라 글씨쓰기 (handwriting), 철자쓰기(spelling), 작문(written expression-composition)의 세 영역으로 구성된다(Berninger, Cartwright, Yates, Swanson, \& Abbott, 1994). 그 중 철자능력은 쓰기의 궁극적 목표 인 작문을 예측하는 요소 중 하나로 성공적인 쓰기를 위해서 선행 되어야 하는 조건이다(MacArthur, Graham, Haynes, \& DeLaPaz, 1996; Martin \& Manno, 1995). 쓰기 발달에 대한 선행연구에서 1 학년 시기에는 자소-음소 일치형 규칙단어에서 $80 \%$ 이상 정확도 가 나타났다(Kim, 2009). 또 Shin, Seol, Cho, Nam과 Pae (2015)에 서는 문법형태소와 관련한 철자 오류가 3학년 시기에 다시 증가하 는 경향을 보였는데, 이는 자소-음소 불일치 단어 쓰기, 복잡한 철 자 지식 이해, 형태소 지식을 이용한 철자 학습이 초등 중학년까지 이루어진다는 것을 말한다.

이러한 쓰기를 예측하는 변인으로는 어휘와 듣기이해를 포함한 언어적 지식과 음운인식, 형태인식, 철자 표기인식의 상위언어적 능 력이 있다(Babayiğit \& Stainthorp, 2011; Berninger et al., 2006; Chung, 2015; Sprenger-Charolles, Siegel, Béchennec, \& Serniclaes, 2003; Kim, 2013). Nagy, Berninger와 Abbott (2006)는 철자 발달
이 이루어질 때는 자소-음소 대응만으로 해석하는 것이 아니라 여 러 수준의 언어적 능력이 필요하기 때문에 상위의 언어적 능력을 습득하여야 한다고 말한다. 읽기와 쓰기 능력에 요구되는 언어적 능력들은 학령기에 접어들었을 때 아동이 이미 가진 정보와 상호 작용을 통하여 새로운 정보를 받아들이는 데 도움을 준다. Van Kleeck (1994)는 상위언어능력을 언어의 성격이나 특성을 의식적 으로 반영할 수 있는 능력으로 상호작용, 문해력 습득, 읽기능력, 학 업과 연관되며 언어이해나 구어(spoken language)보다 문어(written language)에서 더 중요한 역할을 한다고 하였다(Ahn, Heo, \& Seo, 2012; Jarmulowicz, Taran, \& Hay, 2007; Kamhi \& Catts, 2012; Kim \& Jung, 2015). 이러한 상위언어능력의 한 영역인 형태소인식 능력이 최근 읽기, 쓰기를 예측하는 요인으로 언급되고 있으며 (Jung, 2014) 학년이 올라갈수록 형태소인식능력이 읽기와 쓰기에 더욱 많이 관여하게 된다(Apel, Wilson-Fowler, Brimo, \& Perrin, 2012; Cho, Chiu, \& McBride-Chang, 2011; Shin et al., 2015; Wolter, Wood, \& D’zatko, 2009; Yang \& Lee, 2016).

형태소는 의미를 가진 가장 작은 단위를 말하는데 한국어는 형 태소가 풍부한 언어로 굴절어(infection), 합성어(compound), 파생 어(derivative) 등의 형태론적 구조가 있다(Zoh et al., 2003). 굴절어 는 흔히 어근이라고 불리는 실질형태소와 문법형태소의 결합으로 구성되어 있으며, 단어 범주에 변화를 주지 않는다. 단어는 단어를 구성하고 있는 구조에 따라 단일어와 복합어로 나누어진다. 단일어 는 하나의 실질형태소로 된 단어이고, 복합어는 둘 이상의 실질형 태소로 구성된 합성어와 실질형태소와 접사의 결합으로 구성된 파 생어로 이루어진다. 위와 같은 방법으로 단어를 만드는 방법을 조 어법, 단어형성법이라고도 한다. 단어형성법과 관련된 형태소인식 능력(morphological awareness)은 단어를 구성하는 형태소 구조에 대하여 의식적으로 인식하고 조작하는 능력을 말한다(Carlisle, 1995). 형태소인식능력은 철자를 보기 쉽고 빨리 볼 수 있도록 도와 주어 읽기 처리 속도를 향상시켜주고 단락글 이해도 가능하게 한 다(Wolf \& Katzir-Cohen, 2001). 형태소인식능력은 아동기 이후에 도 계속해서 발달한다고 알려져 있으며 합성 및 파생형태소 발달 은 학령기 후기까지 발달이 이루어지고 특히 파생형태소의 경우에 는 중학교 시기 이후까지도 발달한다고 한다(Carlisle, 2003; Goodwin et al., 2012). 초등 저학년 읽기학습부진 아동의 형태소인식능 력을 살펴보았던 국내연구에서는 합성어 과제보다 파생어 과제에 서 수행도가 더 낮게 나타나 파생형태소의 발달이 더 늦게까지 이 루어진다는 결과가 나타났다. 그 중 읽기학습부진 아동의 합성, 파 생 능력이 일반아동보다 더 낮은 것으로 나타났다(Kim \& Jung, 2015). 또한 미국, 중국, 한국의 초등 2 학년을 대상으로 읽기를 비교 
한 Cho, McBride-Chang과 Park (2008)의 언어 간 연구에서는 학 령전에는 음운인식, 형태소인식이 읽기에 모두 영향을 주었지만 초 등 중학년이 될수록 음운인식의 영향력은 줄고 형태소인식 영향력 이 더욱 커진다고 한다. 이와 같은 결과를 포함한 국내외 선행연구 와 문헌을 통하여 형태소인식이 읽기와 관련이 크다는 것을 알 수 있다(Apel, Diehm, \& Apel, 2013; Berninger et al., 2006; Jung, 2014; Kim \& Jung, 2015; Park, 2012; Schiff, Nuri Ben-Shushan, \& BenArtzi, 2017; Siegel, 2008; Wolter \& Green, 2013). 이러한 특성을 바 탕으로 본 연구에서는 형태소인식능력을 살펴보기 위한 하위 변인 으로 합성, 파생을 선택하였으며 국내외 선행연구를 바탕으로 하였 을 때 형태소인식능력이 읽기, 쓰기에 미치는 영향 및 읽기, 쓰기에 어려움을 보이는 아동들의 특성을 살펴보는 데 적절한 능력으로 여겨졌다.

일반아동들은 학령기에 접어들며 고학년에 이를수록 글자 해독 (decoding), 유창하게 읽기, 읽기이해에 많은 주의를 기울이게 된 다. 이러한 일련의 과정에서 어려움을 보이는 아동들을 DSM-5에 서는 특정학습장애(specific learning disorders, SLD)라고 하며 단 어를 읽거나 읽은 내용의 의미를 이해하기 어렵고 쓰기 표현에서 어 려움을 동반하는 등 언어이해 및 표현, 읽기, 쓰기 전반에서 어려움 이 있는 아동으로 정의하였다(American Psychiatric Association, 2013). Kamhi와 Catts (2012)는 취약한 언어 기술로 인해 읽기 어려 움을 겪는 아동들을 언어학습장애로 언급하며 읽기장애(reading disorders)와 같은 아동들로 동일시하였다. 언어학습장애는 신체, 운동, 정서상에 결함이 없다고 보고된 아동으로 동작성 지능이 85 이상, 읽기 부진에 대한 저성취 모델(low achievement model)의 읽 기 성취도 저성취 기준에 따라 $25 \%$ ile 이하(Shaywitz, Escobar, Shaywitz, Fletcher, \& Makuch, 1992)에 속하며, 여러 선행연구에서 공 통된 기준으로 표준화된 언어검사에서 표준점수가 85 이하인 아동 으로 선정하고 있었다(Srivastava \& Gray, 2012; Windsor, Scott, \& Street, 2000). 언어학습장애는 음운론, 구문론, 의미론, 형태론, 화 용론의 언어적인 측면에서 결함을 보인다. 음운인식능력이 낮고 문 법 형태와 구문의 오류를 보이며 형태소에 관한 지식이 부족하다. 더불어 이야기 산출의 어려움과 추론 이해에서도 어려움을 보인다 (Kim, 2016; Leinonen \& Letts, 2001; McGregor, 2009; Oetting \& Hadley, 2009; Pennington \& Bishop, 2009; Scott, 2004). 또한 어휘 량이 제한적이고 비유적 언어 이해가 어렵다. 언어학습장애 아동 은 형태론적 인식에 제약이 있으며, 특히 파생 능력은 일반아동에 비하여 습득이 느리고 수행도가 낮다(Windsor \& Hwang, 1999). 형태를 합성, 파생하여 새롭게 조작하는 능력은 빠르고 자동적인 읽기와 고급화된 철자쓰기에 기여를 한다. 그러나 이러한 능력의
제한은 언어학습장애 아동의 읽기유창성, 철자쓰기에 영향을 미 칠 것이다.

읽기 발달에서 초등 중학년은 해독에서 읽기이해 단계로 전환되 는 시기로 읽기유창성이 완성되고, 쓰기 측면에서는 고급화된 쓰 기 기술인 작문으로 전환되는 시기로 철자가 완성되는 때이다. 하 지만 대부분의 연구에서 단어 수준의 읽기능력이나 읽기이해능력 에 초점을 맞추고 있으며 읽기장애의 하위 분류인 읽기유창성과의 상관을 알아보는 연구는 부족한 모습이다. 특히 읽기유창성의 역 할이 중요하다고 여겨지는 Chall (1983) 읽기발달 3단계에 해당하 는 초등 중학년을 대상으로 한 연구는 더욱 찾아보기 어렵다. 철자 쓰기 연구에서도 언어학습장애를 대상으로 형태소인식능력과 철 자쓰기 관계를 분석한 연구는 부족한 실정이다. 이와 같은 읽기, 쓰 기 능력을 뒷받침해주는 공통적인 요인들을 살펴보는 것은 중요하 며 그 중에서 형태소인식능력은 형태론적으로 합성하고 파생하여 새로운 의미를 만들어내거나 빠른 확인을 할 수 있도록 해준다. 따 라서 본 연구에서는 읽기와 쓰기를 설명하는 요인들 중에서 새롭게 대두되고 있는 형태소인식능력이 읽기와 쓰기에 어떤 작용을 하는 지 알아보고자 하며 읽기의 전환기인 초등 중학년에 이러한 능력이 어떤 영향을 미치는지 알아보고자 한다.

연구 문제는 다음과 같다.

1) 초등 3-4학년 아동의 집단(일반, 언어학습장애)과 과제 유형 (합성, 파생)에 따라 형태소인식능력의 차이가 있는가?

2) 초등 3-4학년 아동의 집단(일반, 언어학습장애)에 따라 읽기 유창성과 철자쓰기의 특성은 어떠한가?

3) 초등 3-4학년 일반아동과 언어학습장애 아동의 형태소인식 능력과 읽기유창성, 철자쓰기 간의 상관관계가 있는가?

\section{연구방법}

\section{연구대상}

본 연구는 부산시 소재의 초등학교에 재학중인 3-4학년 언어학 습장애 아동 16 명, 일반아동 16 명, 총 32 명을 대상으로 하였다. 일 반아동은 부모나 교사에 의해 신체, 정서, 청력에 문제가 없다고 보 고되었으며 한국 비언어 지능검사(Korean version of Comprehensive Test of Nonverbal Intelligence-2, K-CTONI-2; Park, 2014)의 도형척도 지능지수가 80 이상으로 정상에 속하고, 한국어 읽기검 사(Korean Language based Reading Assessment, KOLRA; Pae, Kim, Yoon, \& Jang, 2015)의 읽기지수 2 가 $26 \%$ ile 이상, 학령기 언어 검사(Language Scale for School-aged Children, LSSC; Lee, Heo, \& Jang, 2015)의 전체 언어지수가 95 이상으로 평균 이상인 아동으로 
Table 1. Participants' characteristics

\begin{tabular}{lcr}
\hline & $N C(N=16)$ & $\operatorname{LLD}(\mathrm{N}=16)$ \\
\hline K-CTONI-2 (IO) & $106.57(10.07)$ & $93.50(9.10)$ \\
KOLRA (\%ile) & $67.8(19.1)$ & $5.5(4.54)$ \\
LSSC (LO) & $108.73(8.93)$ & $74.94(8.85)$ \\
\hline
\end{tabular}

Values are presented as mean (SD).

$\mathrm{NC}=$ normal children; $\mathrm{LLD}=$ language-learning disabilities; $\mathrm{K}-\mathrm{CTONI}-2=$ Korean Comprehensive Test of Nonverbal Intelligence-2 (Park, 2014); KOLRA= Korean Language based Reading Assessment (Pae, Kim, Yoon, \& Jang, 2015); LSSC=Language Scale for School-aged Children (Lee, Heo, \& Jang, 2015).

선정하였다.

언어학습장애 아동은 부모나 교사에 의해 신체, 정서, 청력에 문 제가 없다고 보고되었으며 한국 비언어 지능검사(K-CTONI-2)의 도형척도 지능지수가 80 이상으로 정상에 속하고, 저성취 기준(Shaywitz et al., 1992)에 따라 한국어 읽기검사(KOLRA)의 읽기지수 2 가 $25 \%$ ile 이하이며, 학령기 언어검사(LSSC)의 전체 언어지수가 85 미만으로 언어능력이 또래 학년에서 부족한 상태로 특별한 언어 중 재가 필요하다고 판단되는 대상으로 선정하였다(Table 1).

\section{연구도구}

읽기유창성 측정을 위하여 한국어 읽기검사(KOLRA; Pae et al., 2015)를 사용하였으며 본 연구에서는 3-4학년용 '산과 바다'를 사 용하였다.

철자쓰기 능력 측정을 위하여 한국어 읽기검사(KOLRA)의 받 아쓰기를 사용하였다. 받아쓰기 전체 항목 30 개 중 일치형 17 개, 불 일치형 13 개 문항으로 나누어 살펴보았다.

본 연구의 실험도구인 형태소인식검사는 선행연구에서 사용된 Apel과 Lawrence (2011), Cho 등(2011), Jung (2014)의 연구의 과제 를 참고하여 재구성하였다. 본 검사에서는 파생 접사를 포함하여 의미를 가진 형태소인식능력을 측정하기 위해 하위 과제로 합성과 파생의 결합, 분리 과제로 구성되었다. 하위 과제에서 사용될 문항 들은 초등 저학년 수준에서 이해 가능할 만한 어휘로 선정하기 위 하여 초등 저학년 교과서를 기반으로 하였다.

합성 항목은 Jung (2014)의 방법을 기반으로 문항을 재구성하였 으며 합성어 결합 과제 10 문항, 합성어 분리 과제 10 문항, 총 20 문항 으로 구성되었다. 합성어 결합 과제는 두 개의 실질형태소를 결합하 여 새로운 단어를 만들어서 빈칸이 있는 미완성 문장을 완성시키는 과제이다. 합성어 결합 과제의 예는 "유리로 만든 컵을 유리컵이라 고 합니다. 종이로 만든 컵은 무엇이라고 할까요?”의 빈칸을 채우는 것이다. 합성어 분리 과제는 주어진 합성어를 분리하여 빈칸이 있는 미완성 문장을 완성시키는 과제이다. 합성어 분리 과제의 예는 "이
름표"라는 단어를 제시한 후 “새 책을 받으면 가장 먼저 ( )을 써 야한다.”의 빈칸을 채우는 것이다.

파생 항목은 Apel과 Lawrence (2011) 외 다수의 연구자들이 사 용한 방법을 기반으로 문항을 재구성하였으며 파생어 결합 10 문항 과 파생어 분리 과제 10 문항, 총 20 문항으로 구성되었다. 파생어 결 합 과제는 실질형태소가 포함된 단어를 제시한 후 제시된 단어에 적절한 접사를 결합하여 빈칸이 있는 미완성 문장을 완성시키는 과제이다. 파생어 결합 과제의 예는 “부채"라는 단어를 제시한 후, “날씨가 너무 더워서 손으로 ( )을 했다”의 빈칸을 채우는 것이 다. 파생어 분리 과제는 실질형태소와 접사가 결합된 단어를 제시 한 후 접사를 분리하여 빈칸이 있는 미완성 문장을 완성시키는 과 제이다. 파생어 분리 과제의 예는 “겨루기”라는 단어를 제시한 후, "나는 친구와 누가 빨리 달리는지 ( )."의 빈칸을 채우는 것이다.

본 검사는 합성, 파생이 각각 20 문제이며 총 40 문항으로 이루어 졌다. 합성, 파생의 결합과 분리 각 유형의 문항들은 음운론적.형태 론적 투명도를 고려한 문항들로 구성되었다. 결합과 분리 10 문항 중 5 문항은 음운론적.형태론적 투명도가 높아 발음이나 형태가 변하지 않는 문항으로 구성하였고(예: 종이로 만든 컵은? 종이컵), 나머지 5문항은 음운론적.형태론적 투명도가 낮아 발음이나 형태 가 변하는 문항(예: 잇몸 가 썩어서 치과에 갔다)으로 구 성하였다(Appendix 1).

형태소인식 과제에서 쓰인 문항들에 대하여 2명의 학령기 아동 언어발달의 전문가에게 내용타당도를 의뢰하였다. 2 명의 전문가는 모두 언어병리학 박사학위 소지자로 언어병리학 교수이다. 2 명의 전문가가 실험절차, 문항 난이도, 질문 구성, 목표 답변의 적절성에 대한 타당도를 Likert 5 점 척도 $(0=$ 전혀 그렇지 않다, $1=$ 그렇지 않 다, $2=$ 보통이다, $3=$ 그렇다, $4=$ 매우 그렇다)로 평가하였다. 그 결과 실험절차에 대한 타당도는 4점, 문항난이도에 대한 타당도는 3.82, 질문 구성에 대한 타당도는 3.87 , 목표 답변의 적절성에 대한 타당 도는 3.85 로 높은 타당도를 검증받았다.

\section{연구절차}

검사는 소음이 적은 방에서 검사자와 아동이 1:1로 진행하였다. 먼저 선별검사(LSSC, KOLRA, K-CTONI-2)를 통해 집단을 선별 한 후, 본 실험인 형태소인식 과제를 실시하였다.

실험 과제인 형태소인식검사는 검사지 문항을 아동에게 보여주 고 검사자가 문항을 함께 읽어준 뒤 아동이 구어로 대답하도록 하 였다. 연습 문제를 먼저 진행하여 검사에 대한 이해가 충분히 되었 을 때 본 문제로 넘어갔다. 학생들의 반응은 모두 녹음하여 전사한 뒤 분석하였으며 교차균형화(cross-balancing)를 위하여 실험 과 
제를 실시할 때 합성, 파생의 순서를 조절하여 실시하였다.

\section{자료분석}

읽기유창성은 정확성, 속도, 읽기유창성 총점으로 나누어 분석 하였다. 읽기 정확성은 358 음절로 이루어진 문단글의 첫 음절부터 끝 음절까지 정확하게 읽은 음절수를 측정하였으며 소요된 시간 (초)으로 속도를 측정하였다. 읽기유창성 총점은 358 음절의 문단 글을 10 초당 정확하게 읽은 음절수로 측정하였다.

철자쓰기는 자소-음소 일치형, 자소-음소 불일치형 쓰기로 나누 어 분석하였다. 철자쓰기 전체 30 문항 중 일치형 쓰기는 17 문항, 불 일치형 쓰기는 13 문항으로 총 30 문항이었다.

형태소인식능력검사는 질문에 적절한 대답을 한 경우 1점으로 계산하고 오반응 또는 무응답의 경우에는 0 점으로 하여 원점수를 산출하였다. 형태소인식의 과제 유형인 합성, 파생의 점수는 각 20 점이며 총 점수는 40 점 만점이었다.

본 연구에서는 형태소인식능력 과제 분석, 읽기유창성, 철자쓰기 에 대한 신뢰도를 검증하기 위해 전체 자료의 $20 \%$ 를 임의로 선정 하여 검사자 간 신뢰도를 산출하였다. 연구자는 제1평가자이고 3 년 이상의 학령기 언어중재 경험이 있는 언어병리학 석사학위 소지자 1 명을 제 2 평가자로 선정하였다. 형태소인식 과제에 대한 검사자 간 채점신뢰도는 $100 \%$ 로 나타났고 읽기유창성, 철자쓰기에 대한 채 점신뢰도는 각각 $98.9 \%, 100 \%$ 로 나타났다.

\section{통계처리}

첫째, 집단(일반, 언어학습장애)과 과제 유형(파생, 합성)에 따라 형태소인식능력의 차이를 알아보기 위해서 반복측정 이원분산분 석(two-way ANOVA with repeated measure)을 실시하였다. 둘째, 집단(일반, 언어학습장애)에 따라 읽기유창성과 철자쓰기의 특성 을 알아보기 위해서 독립표본 $t$-검정(two-independent samples $t$ test)을 실시하였다. 셋째, 형태소인식능력과 읽기유창성, 철자쓰기 간의 상관관계를 알아보기 위해서 Pearson 상관을 실시하였다.

통계 처리는 IBM SPSS Statistics version 23 프로그램을 이용하 여 분석하였다.

Table 2. Total morphological awareness according to group (raw score)

\begin{tabular}{lccc}
\hline & $\mathrm{NC}(\mathrm{N}=16)$ & $\operatorname{LLD}(\mathrm{N}=16)$ & Total $(\mathrm{N}=32)$ \\
\hline Compound & $18.68(1.35)$ & $14.25(2.35)$ & $16.46(1.85)$ \\
Derivative & $18.06(2.01)$ & $11.18(3.52)$ & $14.62(2.76)$ \\
Total & $35.56(5.07)$ & $25.43(4.78)$ & $30.5(7.07)$ \\
\hline
\end{tabular}

Values are presented as mean (SD).

$N C=$ normal children; $L L D=$ language-learning disabilities .

\section{연구결과}

\section{초등 3-4학년 아동의 집단(일반, 언어학습장애)과 과제 유형(합성, 파생)에 따른 형태소인식능력의 차이}

본 연구에서 살펴본 집단과 형태소인식 과제 유형에 따른 기술통 계 결과는 Table 2와 같다(Figure 1).

형태소인식 과제 유형에 따른 집단 간 차이를 살펴본 결과 $F_{(1,30)}=$ 53.877 ( $p$ <.05)로 언어학습장애 아동의 형태소인식능력이 일반아 동에 비하여 유의미하게 낮았다. 형태소인식 과제 유형에 따른 집 단 내차이를 살펴본 결과 $F_{(1,30)}=556.172(p<.05)$ 로 나타나 유의미 한 차이가 있는 것으로 나타났으며 형태소인식 과제와 집단의 상호 작용 효과를 살펴본 결과 $F_{(1,30)}=5.828(p<.05)$ 로 유의미한 상호작 용 결과가 나타났다.

상호작용에 대한 사후분석으로 집단 간의 형태소인식능력의 차 이를 독립표본 $t$-검정을 통하여 살펴본 결과 언어학습장애 아동은 일반아동에 비하여 파생에서 유의하게 낮은 수행력을 보였으나 $(t=6.772, p<.05)$ 합성에서는 유의한 차이가 나타나지 않았다 $(t=$ $6.542, p>.05)$. 집단 내에서 형태소인식 과제에 따른 차이를 살펴보 고자 대응표본 $t$-검정을 실시한 결과 일반아동은 합성과 파생에서 유의미한 차이를 나타내지 않았으나 $(t=1.576, p>.05)$ 언어학습장 애 아동은 합성과 파생에서 유의미한 차이를 나타냈다 $(t=3.398$, $p<.05)$.

\section{초등 3-4학년 아동의 집단(일반, 언어학습장애)에 따른 읽기유창성과 철자쓰기의 특성 비교}

두 집단의 읽기유창성, 철자쓰기 능력을 살펴보기 위하여 독립 표본 $t$-검정을 실시하였다. 집단과 읽기유창성, 철자쓰기의 $t$-검정 결과는 Table 3 과 같이 나타났다.

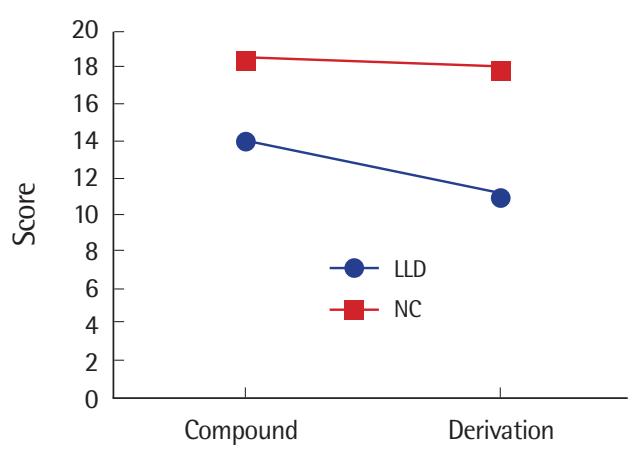

Figure 1. Morphological awareness according to group. $\mathrm{NC}=$ normal children; $\mathrm{LLD}=$ language-learning disabilities . 
Hyo-Jung Han, et al. • Correlation among Morphological Awareness, Reading Fluency and Spelling

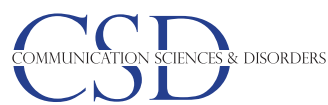

Table 3. Reading fluency and spelling score

\begin{tabular}{lccc}
\hline & $\mathrm{NC}(\mathrm{N}=16)$ & $\operatorname{LLD}(\mathrm{N}=16)$ & $t$ \\
\hline RF total & $40.76(5.17)$ & $23.82(4.83)$ & $9.568^{*}$ \\
Accuracy & $342.37(8.92)$ & $331.50(11.70)$ & $2.955^{*}$ \\
Rate & $91.12(29.78)$ & $143.37(24.09)$ & $-5.455^{*}$ \\
Spelling & $28.93(1.34)$ & $20.25(5.54)$ & $6.093^{*}$ \\
PGC & $16.43(.81)$ & $11.87(2.98)$ & $5.897^{*}$ \\
PGNC & $12.50(.81)$ & $8.37(3.11)$ & $5.121^{*}$ \\
\hline
\end{tabular}

Values are presented as mean (SD).

$\mathrm{NC}=$ normal children; $\mathrm{LLD}=$ language-learning disabilities; $\mathrm{RF}$ total = reading fluency total; accuracy=syllable of correctly reading; $\mathrm{PGC}=$ phoneme-grapheme correspondent; $\mathrm{PGNC}=$ phoneme-grapheme non-correspondent. ${ }^{*} p<.05$.

일반아동과 언어학습장애 아동의 읽기유창성, 철자쓰기 능력에 차이가 있는지 살펴본 결과, 읽기유창성 총점, 정확성, 속도, 철자쓰 기, 자소-음소 일치형 쓰기, 자소-음소 불일치형 쓰기에서 언어학 습장애 아동이 일반아동에 비하여 유의미하게 더 낮은 수행력을 나타냈다.

\section{초등 3-4학년 아동의 형태소인식능력과 읽기유창성, 철자쓰기 간의 상관관계}

일반아동, 언어학습장애 아동의 형태소인식능력과 읽기유창성, 철자쓰기의 수행능력 간의 상관관계를 살펴보기 위하여 Pearson 상관분석을 실시한 결과는 Table 4 와 같다.

일반아동의 형태소인식 과제 유형과 읽기유창성, 철자쓰기의 상 세 유형 간의 상관관계를 살펴보면 파생과 읽기유창성 총점, 속도, 철자쓰기 총점, 일치형 쓰기에서 유의미한 상관이 있는 것으로 나 타났다 $(p<.05, p<.01)$. 반면 형태소인식 총점, 합성은 읽기유창성, 철자쓰기 능력 전체와 유의미한 상관이 나타나지 않았다( $p>.05)$.

언어학습장애 아동의 형태소인식 과제 유형과 읽기유창성, 철자 쓰기의 상세 유형 간의 상관관계를 살펴보면 합성과 형태소인식 총 점에서 정확도와 유의미한 상관이 있는 것으로 나타났다 $(p<.05)$. 반면 형태소인식 과제 모두 철자쓰기 하위영역과는 유의미한 상관 을 나타내지 않았으며 파생은 읽기유창성, 철자쓰기 능력 전체와 유의미한 상관이 나타나지 않았다( $p>.05)$.

\section{논의 및 결론}

본 연구는 초등 3-4학년 언어학습장애 아동과 일반아동의 형태 소인식능력, 읽기유창성, 철자쓰기 능력을 살펴보고 형태소인식능 력과 읽기유창성, 철자쓰기 간의 상관관계에 대해서 살펴보았다.

첫째, 두 집단의 형태소인식능력을 비교하였을 때 언어학습장애
Table 4. Correlation analysis of morphological awareness, reading and writing

\begin{tabular}{lllllllll}
\hline & \multicolumn{3}{c}{ Reading factor } & & \multicolumn{4}{c}{ Writing factor } \\
\cline { 2 - 3 } \cline { 7 - 8 } & RF total & Accuracy & Rate & & Spelling & PGC & PGNC \\
\hline Normal children & & & & & & & \\
$\quad$ Compound & .329 & -.073 & -.391 & & .172 & .314 & -.030 \\
Derivative & $.730^{* *}$ & .440 & $-.689^{* *}$ & & $.545^{*}$ & $.592^{*}$ & .304 \\
Total & .269 & .197 & -.278 & & .055 & .146 & -.056 \\
LLD children & & & & & & & \\
Compound & .155 & $.511^{*}$ & -.029 & & .123 & .138 & .086 \\
Derivative & .442 & .338 & -.413 & & .407 & .446 & .296 \\
Total & .401 & $.500^{*}$ & -.318 & & .360 & .396 & .261 \\
\hline
\end{tabular}

$\mathrm{NC}=$ normal children; $\mathrm{LLD}=$ language-learning disabilities; $\mathrm{RF}$ total = reading fluency total; accuracy= syllable of correctly reading; $\mathrm{PGC}=$ phoneme-grapheme correspondent; $\mathrm{PGNC}=$ phoneme-grapheme non-correspondent. ${ }^{*} p<.05,{ }^{* *} p<.01$.

아동의 형태소인식능력은 일반아동에 비하여 유의미하게 저조한 것으로 나타났다 $\left(F_{(1,30)}=79.103, p<.05\right)$. 상위언어능력 중 하나로 알려진 형태소인식능력이 읽기, 쓰기 능력과 관련된다는 문헌을 바 탕으로 하였을 때 형태소인식능력에서 어려움을 보이는 언어학습장 애는 읽기, 쓰기에서도 어려움이 지속될 것이라는 것을 알 수 있다.

형태소인식능력의 과제 유형별 차이를 살펴보았을 때 합성, 파생 순서로 유의미한 차이가 나타났다. 합성 능력은 학령기 초기에 습득 이 이루어진다고 보고되고 있으며(Carlisle, 2003) 합성보다 파생의 수행도가 더 낮게 나타난 본 연구의 결과가 선행연구를 지지해주 고 있다. 어근과 어근을 더하여 새로운 단어를 만들어내는 합성 능 력은 의미와 의미를 더하여 새로운 단어를 만들어내는 전략을 이 해하여 문맥 속에서 의미를 파악하는 데 도움이 될 것으로 이는 읽 기의 최종 목표인 읽기이해에도 긍정적인 영향을 미치게 될 것이다.

집단과 과제유형에 따른 상호작용 효과를 살펴보았을 때 유의미 한 효과가 나타났다 $\left(F_{(1,30)}=66.164, p<.05\right)$. 일반아동은 합성, 파생 순서로 높은 수행도를 보였으나 합성과 파생 간의 유의미한차이가 나타나지 않았다. 합성은 어근과 어근을 더하여 새로운 단어를 만 들어내는 것이고 파생은 어근에 접사를 더하여 단어를 만드는 것 으로 본 연구에서 일반아동의 합성과 파생은 매우 높은 수행도를 보였다. 이는 초등 1-3학년을 대상으로 한 선행연구에서 합성보다 파생 점수가 더 낮게 나타났다는 것과 다른 결과이다(Kim \& Jung, 2015). 즉 초등 중학년에 도달하면 파생 능력도 합성만큼 높은 단계 에 도달한다는 것을 본 연구를 통해 알수 있다.

언어학습장애 아동도 합성, 파생의 순서로 높은 수행도를 나타 냈다. 그러나 일반아동과 달리 합성과 파생 간 유의미한 차이를 보 였다. 저학년의 형태소인식능력을 살펴본 선행연구에서는 저학년 의 파생 능력이 합성능력보다 유의하게 더 낮게 나타났다(Kim \& 
Jung, 2015). 본 연구에서 살펴본 초등 3-4학년 언어학습장애 아동 의 파생 능력은 선행연구의 저학년 일반아동과 유사한 수행 패턴 을 보이고 있으며 이를 통하여 언어학습장애 아동의 파생 능력이 저조한 수준에 있음을 알 수 있었다.

언어학습장애 아동과 일반아동이 형태소인식능력의 어떤 부분 에서 차이를 보였는지 집단 간 차이를 살펴보았다. 그 결과합성, 파 생 모두 언어학습장애 아동이 일반아동보다 낮은 수행도를 보였으 나 합성은 두 집단 간 유의미한 차이를 보이지 않았다. 저학년 읽기 학습부진을 대상으로 한 선행연구에서는 일반아동에 비하여 부진 아동의 수행도가 유의하게 낮았지만(Kim \& Jung, 2015) 본 연구에 서 일반아동은 만점에 가까운 합성 능력을 나타냈고 언어학습장 애 아동의 합성 능력도 일반아동과 유의한 차이를 보이지 않았다. 이는 언어학습장애 아동도 초기에 발달하는 합성 능력은 초등 중 학년에 이르면 일반아동과 유사한 수행도를 보이는 것을 의미한다.

파생은 어근과 접사를 더하여 새로운 어휘를 만드는 방법으로 이러한 파생 능력은 언어학습장애 아동이 일반아동에 비하여 유 의미하게 낮은 수준으로 나타났다. 이는 언어학습장애 아동의 파 생 능력이 일반아동에 비하여 습득이 느리고 수행도가 낮다고 밝 힌 선행연구를 뒷받침하는 결과이다(Windsor \& Hwang, 1999). 파 생 능력은 단어를 분절하고 파생하여 새로운 의미를 만들어내고 해석하는 것을 가능하게 하며 주어진 단어의 철자를 시각적으로 보기 쉽게 인식하는 것을 도와주어 더 빨리 볼 수 있게 해준다(Anglin, Miller, \& Wakefield, 1993; Carlisle, 2000; Siegel, 2008). 이러 한 파생 능력은 쓰기 발달 단계에서도 살펴볼 수 있다. Ehri (1987) 의 철자쓰기 단계에서 파생 단계(derivational relations)를 거치며 어근(root word)과 파생(derivations) 방식을 이해하고 단어를 효과 적으로 만들어 낼 수 있게 된다. 파생 단계를 거쳤을 때 고급의 철자 기술을 구사하여 쓰기의 궁극적 목표인 작문으로 나아갈 수 있다 고 언급한 바 있다. 하지만 언어학습장애는 이와 같은 방법으로 읽 기, 쓰기 발달을 도와주는 파생 능력에서 어려움을 보이므로 읽기 유창성, 철자쓰기에서도 어려움을 보일 것을 예측할 수 있으며 나 아가 읽기와 쓰기 능력 성취에도 어려움을 보일 것을 알 수 있다.

둘째, 언어학습장애 아동은 일반아동보다 낮은 읽기유창성, 철 자쓰기 능력을 보였다. 읽기유창성과 철자쓰기를 더욱 자세히 살펴 보기 위하여 읽기유창성을 정확도와 속도로, 쓰기를 일치형 쓰기, 불일치형 쓰기로 나누어 살펴보았고 이 모두에서 언어학습장애 아 동이 일반아동보다 수행도가 더 낮았다. 읽기유창성, 철자쓰기는 읽기와 쓰기의 최종 목표인 읽기이해와 작문을 선행하는 요소로 알려져 있다(Hoover \& Gough, 1990; Kim, Lee, \& Shin, 2009). 중 학년에는 읽기유창성이 정확성과 속도를 갖춘 자동성에 도달하는
단계로 읽기이해 단계로 전환되는 시기이고 다양한 철자쓰기가 가 능해지며 작문의 단계로 넘어가는 시기이다(Chall, 1983; Gentry, 2004). 하지만 이러한 능력에서 어려움을 보이는 언어학습장애는 읽기, 쓰기의 궁극적 목표에 도달하는 데 어려움이 있을 것이다.

셋째, 형태소인식능력과 읽기유창성, 철자쓰기 간의 상관관계를 살펴본 결과 일반아동은 파생과 읽기유창성, 속도, 철자쓰기 총점, 일치형 쓰기에서 유의미한 상관이 나타났다. 특히 파생과 속도 간 의 상관관계를 통하여 중학년 시기가 되면 일반아동은 형태소인식 능력을 자동적으로 읽는 데에 사용한다는 것을 알 수 있었으며 파 생 능력이 주로 요구되는 것을 알 수 있다. 파생은 단어를 분절, 파 생하여 새롭게 만들기를 가능하게 하고 시각적으로 빨리 볼 수 있 게 도와준다(Siegel, 2008). 이러한 능력은 단어의 빠른 확인을 가 능하게 하여 읽기 속도 향상에 도움을 준다. 또한 파생은 철자쓰기 와도 상관관계를 나타냈는데 이는 일치형 쓰기에 음운처리, 표기처 리, 형태처리 능력이 요구된다는 선행연구를 지지하는 결과이다 (Kim, 2009). 반면 불일치형 쓰기와 형태소인식에서 상관관계가 나 타나지 않았다. 선행연구들에서 불일치형 쓰기에 형태소인식능력 이 영향을 미친다고 알려져 있다(Lee, Shin, Yoon, \& Pae, 2015; Shin et al., 2015). 그러나 본 연구에서는 일반아동은 만점에 가까운 철자 쓰기 점수와 높은 형태소인식능력을 보였고 이 두 능력에서 모두 매우 높은 수행도를 보여 둘 간의 상관관계는 나타나지 않았다.

언어학습장애 아동의 형태소인식능력과 읽기유창성, 철자쓰기 간의 상관관계를 살펴본 결과 형태소인식 총점과 합성이 정확도와 유의미한 상관이 나타났다. 언어학습장애 아동은 형태소인식능력 을 정확하게 읽는 데 사용하고 있으며 합성 능력이 주로 사용되었 다. 우리말의 $60 \%$ 이상이 합성어로 이루어졌다는 특성 $(\mathrm{Yi} \& \mathrm{Yi}$, 1999)이 있으므로 합성 능력이 여기에 잘 활용될 수 있을 것이다. 하지만 속도와는 어떠한 상관관계를 나타나지 않았다. 이는 언어 학습장애 아동은 아직 읽기의 자동성 단계에 도달하지 못한 것을 알 수 있으며 글을 정확하게 읽기 위하여 형태소인식능력을 사용하 고 있는 것을 알 수 있다. 일반아동의 경우 파생 능력이 속도와 상 관이 나타나 자동적 읽기를 가능하게 했다. 하지만 언어학습장애 아동의 파생 능력은 일반아동에 비하여 유의미하게 낮은 수준으 로 나타났으며 파생 능력을 바탕으로 한 자동성 발달 단계에 도달 하지 못한 것을 알 수 있다. 즉 언어학습장애 아동은 읽기의 정확성 단계를 거쳐가고 있는 것으로 확인되었고 언어학습장애 아동의 자 동성 향상을 위하여 파생 능력의 강조가 요구된다. 반면 언어학습 장애 아동은 철자쓰기 하위 변인에서 모두 유의미한 상관이 나타 나지 않아 철자쓰기 발달에서 형태소인식능력이 활용되고 있지 않 았다. 철자쓰기 발달을 위해서는 어휘, 듣기이해, 음운인식, 철자인 
Hyo-Jung Han, et al. • Correlation among Morphological Awareness, Reading Fluency and Spelling

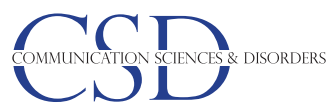

식, 철자표기인식 등의 언어적 능력들이 요구되며 선행연구에서는 초등 저학년 시기의 쓰기에는 음운적 지식이 많이 관여되지만 점 차 형태소인식능력으로 그 비율이 변화한다고 하였다(Apel et al., 2012; Cho et al., 2011; Wolter et al., 2009; Yang \& Lee, 2016). 하지 만 언어학습장애 아동은 이러한 통합적인 언어능력 중 형태론적 능력이 낮기 때문에 정확하게 쓰기에 활용하여 쓰는 데 어려움을 보이고 있는 것으로 나타났다. 이를 바탕으로 하였을 때 철자쓰기 발달에서 어려움을 보이는 언어학습장애 아동은 중학년에 도달하 여서도 형태소인식능력을 철자쓰기에 활용하는 데 어려움을 보이 는 것을 알수 있다.

본 연구에서는 형태소인식능력과 읽기유창성, 철자쓰기 간의 상 관관계를 살펴보았다. 형태소인식능력이 읽기, 쓰기 능력을 예측하 는 상위언어적 능력으로서 읽기유창성, 철자쓰기와 상관이 있다는 것이 선행연구와 본 연구에서 드러났다. 본 연구에서는 형태소인식 의 전반적인 영역을 다루지 못하였으나 이후 연구에서는 어휘형태 소에 대해 살펴보고 어휘형태소 측면에서 어휘의 양을 살펴볼 필 요가 있음을 제언한다. 또한 초등 고학년에서 발달적 변화는 어떠 한지 살펴볼 후속연구를 제안한다.

\section{REFERENCES}

Ahn, S. W., Heo, M. J., \& Seo, J. H. (2012). A study on a phonological awareness of preschoolers in South Korea: exploring the effects of letter knowledge, letter-sound correspondence, ages, and working memory on the phonological awareness. Journal of Speech-Language and Hearing Disorders, 21, 365-388.

American Psychiatric Association. (2013). Diagnostic and statistical manual of mental disorders (DSM-5). Washington, DC: Author.

Anglin, J. M., Miller, G. A., \& Wakefield, P. C. (1993). Vocabulary development: a morphological analysis. Monographs of the Society for Research in Child Development, 58, 1-186.

Apel, K., \& Lawrence, J. (2011). Contributions of morphological awareness skills to word-level reading and spelling in first-grade children with and without speech sound disorder. Journal of Speech, Language, and Hearing Research, 54, 1312-1327.

Apel, K., \& Thomas-Tate, S. (2009). Morphological awareness skills of fourthgrade African American students. Language, Speech, and Hearing Services in Schools, 40, 312-324.

Apel, K., Diehm, E., \& Apel, L. (2013). Using multiple measures of morphological awareness to assess its relation to reading. Topics in Language Dis- orders, 33, 42-56.

Apel, K., Wilson-Fowler, E. B., Brimo, D., \& Perrin, N. A. (2012). Metalinguistic contributions to reading and spelling in second and third grade students. Reading and Writing, 25, 1283-1305.

Babayiğit, S., \& Stainthorp, R. (2011). Modeling the relationships between cognitive-linguistic skills and literacy skills: new insights from a transparent orthography. Journal of Educational Psychology, 103, 169-189.

Bashir, A. S., \& Hook, P. E. (2009). Fluency: a key link between word identification and comprehension. Language, Speech, and Hearing Services in Schools, 40, 196-200.

Berninger, V. W., Abbott, R. D., Billingsley, F., \& Nagy, W. (2001). Processes underlying timing and fluency of reading: efficiency, automaticity, coordination, and morphological awareness. In M. Wolf (Ed.), Dyslexia, fluency, and the brain (pp. 383-414). Austin, TX: Pro-Ed.

Berninger, V. W., Abbott, R. D., Jones, J., Wolf, B. J., Gould, L., Anderson-Youngstrom, M., ... \& Apel, K. (2006). Early development of language by hand: composing, reading, listening, and speaking connections; three letter-writing modes; and fast mapping in spelling. Developmental Neuropsychology, 29, 61-92.

Berninger, V. W., Cartwright, A. C., Yates, C. M., Swanson, H. L., \& Abbott, R. D. (1994). Developmental skills related to writing and reading acquisition in the intermediate grades. Reading and Writing, 6, 161-196.

Carlisle, J. F. (1995). Morphological awareness and early reading achievement. In L. B. Feldman (Ed.), Morphological aspects of language processing (pp. 189-209). Hillsdale, NJ: Lawrence Erlbaum Associates.

Carlisle, J. F. (2000). Awareness of the structure and meaning of morphologically complex words: impact on reading. Reading and Writing, 12, 169-190.

Carlisle, J. F. (2003). Morphology matters in learning to read: a commentary. Reading Psychology, 24, 291-322.

Carlisle, J., \& Rice, M. S. (2002). Improving reading comprehension: researchbased principles and practices. Baltimore, MD: York Press.

Chall, J. S. (1983). Stages of reading development. New York, NJ: McGraw-Hill. Cho, J. R., Chiu, M. M., \& McBride-Chang, C. (2011). Morphological awareness, phonological awareness, and literacy development in Korean and English: a 2-year longitudinal study. Scientific Studies of Reading, 15, 383408.

Cho, J. R., McBride-Chang, C., \& Park, S. G. (2008). Phonological awareness and morphological awareness: differential associations to regular and irregular word recognition in early Korean Hangul readers. Reading and Writing, 21, 255-274. 
Chung, B. J. (2015). Orthographic awareness and related components in children in grades 1 through 4. Journal of Speech-Language \& Hearing Disorders, 24, 63-71.

Ehri, L. C. (1987). Learning to read and spell words. Journal of Reading Behavior, 19, 5-31.

Gentry, J. R. (2004). The science of spelling: the explicit specifics that make great readers and writers (and spellers!). Portsmouth, $\mathrm{NH}$ : Heinemann.

Goodwin, A. P., Huggins, A. C., Carlo, M., Malabonga, V., Kenyon, D., Louguit, M., \& August, D. (2012). Development and validation of extract the base: an English derivational morphology test for third through fifth grade monolingual students and Spanish-speaking English language learners Language Testing, 29, 265-289.

Hoover, W. A., \& Gough, P. B. (1990). The simple view of reading. Reading and Writing, 2, 127-160.

Jarmulowicz, L., Taran, V. L., \& Hay, S. E. (2007). Third graders' metalinguistic skills, reading skills, and stress production in derived English words. Journal of Speech, Language, and Hearing Research, 50, 1593-1605.

Jung, K. H. (2014). Morphological awareness and reading ability of schoolaged children from grades 1 to 3. Communication Sciences \& Disorders, 19, 21-30.

Kamhi, A. G., \& Catts, H. W. (2012). Language and reading disabilities (3rd ed.). Boston, MA: Allyn and Bacon.

Katzir, T., Kim, Y., Wolf, M., O’Brien, B., Kennedy, B., Lovett, M., \& Morris, R. (2006). Reading fluency: the whole is more than the parts. Annals of Dyslexia, 56, 51-82.

Kim, A. H. (2009). Spelling skills of elementary students in Korea: focusing on spelling accuracy and error patterns. Journal of Elementary Education, $22,85-113$.

Kim, A. H. (2013). A preliminary study on predictors for elementary students' writing. Communication Sciences \& Disorders, 18, 66-75.

Kim, A. H., Yoo, H. S., Hwang, M., Kim, U. J., \& Koh, S. R. (2010). Prediction of reading comprehension in elementary school students. Korean Journal of Communication \& Disorders, 15, 357-380.

Kim, D. I., Lee, D. S., \& Shin, J. H. (2009). Introduction to learning disabilities. Seoul: Hakgisa.

Kim, J. Y. (2016). Characteristics of reading related factors in subgroups with language learning disorders. Journal of Learner-Centered Curriculum and Instruction, 16, 339-353.

Kim, S. H., \& Jung, K. H. (2015). Morphological awareness and reading abilities for early elementary school students with poor reading skill. Journal of
Speech \& Hearing Disorders, 24, 35-47.

Kim, Y. S., Wagner, R. K., \& Lopez, D. (2012). Developmental relations between reading fluency and reading comprehension: a longitudinal study from Grade 1 to Grade 2. Journal of Experimental Child Psychology, 113, 93-111.

Lee, I. H., \& Kim, D. I. (2003). The relationship between reading fluency and reading comprehension in primary grades. Korean Journal of Educational Psychology, 17, 1-24.

Lee, J. G., Shin, G. Y., Yoon, H. J., \& Pae, S. (2015). Morpheme and orthographic knowledge based writing intervention for children with poor orthographic knowledge. Journal of Learner-Centered Curriculum and Instruction, 15, 139-156.

Lee, Y., Heo, H., \& Jang, S. (2015). Language Scale for School-aged Children (LSSC). Seoul: Hakjisa.

Leinonen, C., \& Letts, E. (2001). Comprehension of inferential meaning in language-impaired and language normal children. International Journal of Language \& Communication Disorders, 36, 307-328.

MacArthur, C. A., Graham, S., Haynes, J. B., \& De LaPaz, S. (1996). Spelling checkers and students with learning disabilities: performance comparisons and impact on spelling. The Journal of Special Education, 30, 35-57.

Martin, K. F., \& Manno, C. (1995). Use of a check-off system to improve middle school students' story compositions. Journal of Learning Disabilities, $28,139-149$.

McGregor, K. K. (2009). Semantics in child language disorders. In R. G. Schwartz (Ed.), Handbook of child language disorders (pp. 365-387). New York, NY: Psychology Press.

Nagy, W., Berninger, V. W., \& Abbott, R. D. (2006). Contributions of morphology beyond phonology to literacy outcomes of upper elementary and middle-school students. Journal of Educational Psychology, 98, 134-147.

Oetting, J. B., \& Hadley, P. A. (2009). Morphosyntax in child language disorders. In R. G. Schwartz (Ed.), Handbook of child language disorders (pp. 341-364). New York, NY: Psychology Press.

Pae, S., Kim, M., Yoon, H. J., \& Jang, S. (2015). Korean Language Based Reading Assessment (KOLRA). Seoul: Hakjisa.

Park, H. (2014). Korean version of Comprehensive Test of Nonverbal Intelligence Second Edition (K-CTONI-2). Seoul: Mindpress.

Park, S. (2012). A study on the literacy of underachievers. The Journal of Special Children Education, 14, 27-51.

Pennington, B. F., \& Bishop, D. V. (2009). Relations among speech, language, and reading disorders. Annual Review of Psychology, 60, 283-306. 
Hyo-Jung Han, et al. • Correlation among Morphological Awareness, Reading Fluency and Spelling

Schiff, R., Nuri Ben-Shushan, Y., \& Ben-Artzi, E. (2017). Metacognitive strategies: a foundation for early word spelling and reading in kindergartners with SLI. Journal of Learning Disabilities, 50, 143-157.

Scott, C. (2004). Syntactic ability in children and adolescents with language and learning disabilities. In R. A. Berman (Ed.), Language development across childhood and adolescence (pp. 111-133). Amsterdam: John Benjamins Publishing Company.

Shaywitz, S. E., Escobar, M. D., Shaywitz, B. A., Fletcher, J. M., \& Makuch, R. (1992). Evidence that dyslexia may represent the lower tail of a normal distribution of reading ability. New England Journal of Medicine, 326, 145150.

Shin, G. Y., Seol, A. Y., Cho, H. S., Nam, K. C., \& Pae, S. (2015). Korean spelling development and linguistic patterns. Journal of Speech-Language \& Hearing Disorders, 24, 61-72.

Siegel, L. S. (2008). Morphological awareness skills of English language learners and children with dyslexia. Topics in Language Disorders, 28, 15-27.

Sprenger-Charolles, L., Siegel, L. S., Béchennec, D., \& Serniclaes, W. (2003). Development of phonological and orthographic processing in reading aloud, in silent reading, and in spelling: a four-year longitudinal study. Journal of Experimental Child Psychology, 84, 194-217.

Srivastava, P., \& Gray, S. (2012). Computer-based and paper-based reading comprehension in adolescents with typical language development and language-learning disabilities. Language, Speech, and Hearing Services in Schools, 43, 424-437.

Torgesen, J. K., \& Hudson, R. F. (2006). Reading fluency: critical issues for struggling readers. In S. Jay Samuels \& A. E. Farstrup (Eds.), What research has to say about fluency instruction (pp. 130-158). Newark, DE: International Reading Association.
Van Kleeck, A. (1994). Potential cultural bias in training parents as conversational partners with their children who have delays in language development. American Journal of Speech-Language Pathology, 3, 67-78.

Windsor, J., \& Hwang, M. (1999). Derivational suffix productivity for students with and without language-learning disabilities. Journal of Speech, Language, and Hearing Research, 42, 220-230.

Windsor, J., Scott, C. M., \& Street, C. K. (2000). Verb and noun morphology in the spoken and written language of children with language learning disabilities. Journal of Speech, Language, and Hearing Research, 43, 13221336.

Wolf, M. (2007). Proust and the squid: the story and science of the reading brain. New York, NY: HarperCollins Publishers.

Wolf, M., \& Katzir-Cohen, T. (2001). Reading fluency and its intervention. Scientific Studies of Reading, 5, 211-239.

Wolter, J. A., \& Green, L. (2013). Morphological awareness intervention in school-age children with language and literacy deficits: a case study. Topics in Language Disorders, 33, 27-41.

Wolter, J. A., Wood, A., \& D'zatko, K. W. (2009). The influence of morphological awareness on the literacy development of first-grade children. Language, Speech, and Hearing Services in Schools, 40, 286-298.

Yang, M., \& Lee, A. (2016). Influences of linguistic awareness on primary grade children's spelling abilities. The Korea Journal of Learning Disabilities, 13, 67-90.

Yi, K., \& Yi, I. (1999). Morphological processing in Korean word recognition. Korean Journal of Experimental and Cognitive Psychology, 11, 77-91.

Zoh, M. H., Lee, J. M., Kim, J. O., Shin, H. J., Lee, K. O., Do, K. S., ... \& Jung, H. S. (2003). Psychology of language. Seoul: Hakjisa. 
Appendix 1. 형태소인식 과제 유형

\begin{tabular}{|c|c|c|c|}
\hline \multicolumn{2}{|c|}{ 과제유형 } & 예 & 답 \\
\hline 합성 & 결합 & $\begin{array}{l}\text { 유리로 만든 컵을 유리컵이라고 합니다. } \\
\text { 종이로 만든 컵을 무엇이라고 할까요? } \\
\text { 옷을 넣어두는 장을 옷장이라고 합니다. } \\
\text { 책을 넣어두는 장을 무엇이라고 할까요? }\end{array}$ & $\begin{array}{l}\text { 종이컵 } \\
\text { 책장 }\end{array}$ \\
\hline & & & 제시단어 \\
\hline 합성 & 분리 & $\begin{array}{l}\text { 새 책을 받으면 가장 먼저 ( } \quad) \text { 을 써야 한다. } \\
(\quad) \text { 가 썩어서 치과에 갔다. }\end{array}$ & $\begin{array}{l}\text { 이름표 } \\
\text { 잇몸 }\end{array}$ \\
\hline 파생 & 결합 & $\begin{array}{l}\text { 날씨가 너무 더워서 손으로 ( }) \text { 을 했다. } \\
\text { 나는 }(\quad) \text { 를 많이 타서 늘 부채를 갖고 다닌다. }\end{array}$ & $\begin{array}{l}\text { 부채 } \\
\text { 덥다 }\end{array}$ \\
\hline & 분리 & $\begin{array}{l}\text { 나는 친구와 누가 빨리 달리는지 }(\quad) . \\
\text { 지난밤에는 너무 추워서 이불을 꼭 }(\quad ） \text { 잤다. }\end{array}$ & $\begin{array}{l}\text { 겨루기 } \\
\text { 덮밥 }\end{array}$ \\
\hline
\end{tabular}




\section{국문초록}

\section{초등 3-4학년 언어학습장애 아동의 형태소인식능력과 읽기유창성, 철자쓰기 간의 상관관계 한효정 $\cdot$ 김미배 ${ }^{2}$ \\ '부산가톨릭대학교 대학원 언어청각치료학과, ${ }^{2}$ 부산가톨릭대학교 언어청각치료학과}

배경 및 목적: 초등 3-4학년 언어학습장애 아동들의 읽기유창성, 철자쓰기 능력을 살펴보고 읽기와 쓰기를 설명하는 요인들 중에서 새롭게 대두되고 있는 형태소인식능력이 읽기와 쓰기에 어떤 상관관계가 있는지 알아보았다. 방법: 초등학교 3-4학년에 재학 중인 언어 학습장애 16 명, 학년과 지역을 일치시킨 일반아동 16 명, 총 32 명을 대상으로 하였다. 형태소인식검사는 합성, 파생으로 살펴보았다. 읽 기유창성과 철자쓰기는 한국어 읽기검사(KOLRA)의 읽기유창성, 받아쓰기를 사용하였으며 읽기유창성은 속도와 정확성으로 살펴보 았고 철자쓰기는 자소-음소 일치형 쓰기, 불일치형 쓰기로 나누어 살펴보았다. 결과: 언어학습장애 아동의 형태소인식능력, 읽기유창 성, 철자쓰기 능력이 일반아동에 비하여 유의미하게 낮았다. 일반아동은 형태소인식능력과 읽기유창성, 철자쓰기에서 유의미한 상관 이 나타났고 특히 파생은 속도와 일치형 쓰기에서 유의한 상관이 나타났다. 언어학습장애는 형태소인식능력과 읽기유창성, 철자쓰기 와 유의한 상관이 나타났고 합성과 정확성, 일치형 쓰기에서 유의한 상관이 나타났다. 논의 및 결론: 본 연구에서는 초등 3-4학년 언어 학습장애 아동의 읽기유창성, 철자쓰기 능력이 형태소인식능력과 어떤 상관관계를 보이는지 확인하였다. 일반아동의 경우 파생 능력 이 자동적으로 읽기와 정확하게 쓰기에 영향을 미쳤고 언어학습장애는 형태소인식능력을 아직 정확하게 읽는 데에 사용하고 있었다. 따라서 읽기유창성, 철자쓰기의 결함을 언어능력과 연결하여 확인할 필요가 있으며 중재 계획을 설정할 때 형태소인식능력을 고려한 다면 도움이 될 것이라는 것을 시사한다.

핵심어: 학령기, 언어학습장애, 형태소인식능력, 읽기유창성, 철자쓰기

본 연구는 제1저자의 석사학위논문을 수정 및 보완하였음.

\section{참고문헌}

김동일, 이대식, 신종호(2009). 학습장애아동의 이해와 교육 2판. 서울: 학지사.

김순호, 정경희(2015). 초등 저학년 읽기학습부진아동의 형태소인식과 읽기능력. 언어치료연구, 24, 35-47.

김애화(2009). 초등학교 학생의 철자 특성 연구: 철자 발달 패턴 및 오류 유형 분석. 초등교육연구, 22, 85-113.

김애화(2013). 초등학교 학생의 쓰기능력 예측변인에 관한 예비 연구. 언어청각장애연구, 18, 66-75.

김애화, 유현실, 황민아, 김의정, 고성룡(2010). 초등학생의 읽기이해 능력 예측 변인에 관한 연구. 언어청각장애연구, 15, 357-380.

김주영(2016). 하위유형별 언어학습장애 아동의 읽기 관련 요인 특성. 학습자중심교육과학연구, 16,339-353.

박순길(2012). 학습부진아동의 문식성 연구. 특수아동교육연구, 14, 27-51.

박혜원(2014). 한국 비언어지능검사 2판(K-CTONI-2). 서울: 마인드프레스.

배소영, 김미배, 윤효진, 장승민(2015). 한국어 읽기검사(KOLRA). 서울: 학지사.

신가영, 설아영, 조혜숙, 남기춘, 배소영(2015). 초등학생의 철자 발달과 오류 패턴 분석. 언어치료연구, 24, 61-72.

안성우, 허민정, 서중현(2012). 학령전기 유아의 음운인식능력에 관한 연구: 낱자지식, 자소-음소 대응지식, 연령과 작업기억과의 관련성 탐색. 언어치

료연구, 21, 365-388.

양민화, 이애진(2016). 학령기 초기 아동의 철자 기술에 미치는 언어학적 인식 능력의 영향력 변화. 학습장애연구, 13, 67-90.

이광오, 이인선(1999). 한글단어의 인지과정에서 형태소 정보처리. 한국심리학회지: 인지 및 생물, 11, 77-91.

이윤경, 허현숙, 장승민(2015). 학령기 아동 언어검사(LSSC). 서울: 학지사.

이일화, 김동일(2003). 읽기유창성과 독해력 수준과의 관계. 교육심리연구, 17, 1-24. 
이재국, 신가영, 윤효진, 배소영(2015). 쓰기부진 초등생의 형태소 및 철자지식을 활용한 문장쓰기 중재 효과. 학습자중심교과교육연구, 15, 139-156. 정경희(2014). 1-3학년 학령기 아동의 형태소인식과 읽기능력. 언어청각장애연구, 19, 21-30.

정부자(2015). 초등 1-4학년 아동의 철자인식 발달특성과 관련 요인. 언어치료연구, 24, 63-71.

조명한, 이정모, 김정오, 신현정, 이광오, 도경수, 이양, 이현진, 김영진, 김소영, 고성룡, 정혜선(2003). 언어심리학. 서울: 학지사. 